\title{
Liver dialysis: a bridge to liver transplantation or regeneration
}

\author{
B H N Yasmeen ${ }^{1}$
}

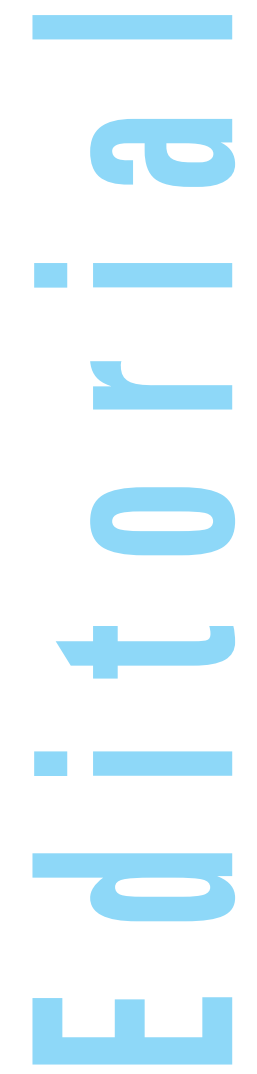

1 Prof. Dr. B H Nazma Yasmeen MBBS, MCPS, MD (Paed) Editor

Northern International Medical College Journal

\section{Professor and Head} Dept. of Paediatrics Northern International Medical College, Dhaka e-mail :

prof.nazma.yasmeen@gmail.com

It's true that most of the physicians are familiar with kidney dialysis not with liver dialysis. While kidney dialysis is found everywhere in USA with more than 2,400 across the nation patients receiving it, liver dialysis is rare. Just over a dozen U.S. hospitals offer liver dialysis; only three of them specialize in pediatrics. ${ }^{1}$ Recently this very new technology is also introduced in our country.

Liver dialysis (LD) refers to the use of extra corporeal devices for temporary support when the liver fails. It is a detoxification treatment for liver failure which is similar to renal hemodialysis and based on the same principles. ${ }^{2}$ It is a form of artificial liver support by a bioartificial liver device. ${ }^{3,4}$ Liver transplantation is the only established treatment for patients who do not respond to medical management.

However, the supply of organs for transplant is limited. Artificial liver support, LD therapies are available to support patients in acute liver failure to allow time for liver recovery or to provide a bridge to transplantation. ${ }^{5}$

For LD devices currently following are used
a) Single Pass Albumin Dialysis (SPAD)
b) Molecular Adsorbent Recirculating System
(MARS) c) Prometheus system d) Dialive

\section{Single Pass Albumin Dialysis (SPAD)}

SPAD system (Germany), designed to remove protein-bound toxins, is the simplest form of albumin dialysis using the basic principles of hemodialysis or hemodiafiltration. It allows the removal of albumin-bound molecules that are small enough to pass through a membrane pores as well as water-soluble toxins. This technique is similar to continuous venovenous hemofiltration; the difference is the dialysate composition and the time of treatment.

In general, SPAD is easy to establish because it can be accomplished with standard dialysis equipment and is therefore widely applicable. ${ }^{6}$ There are several case reports of its clinical use with promising results. ${ }^{7,8}$

\section{Molecular Adsorbent Recirculating System (MARS)}

MARS is the best known extracorporal liver dialysis system and has existed for about more than a decade. It is consisting of two separate dialysis circuits. The first circuit consists of human serum albumin, is in contact with the patient's blood through a semipermeable membrane and has two filters to clean the albumin after it has absorbed toxins from the patient's blood. The second circuit consists of a hemodialysis machine and is used to clean the albumin in the first circuit, before it is recirculated to the semipermeable membrane in contact with the patient's blood. ${ }^{9}$

More than 9,000 patients from 45 countries have now been treated worldwide with the device. ${ }^{10}$

\section{Prometheus system}

In contrast to MARS it is based on albumin permeable membrane with a pore size of 300 $\mathrm{kDa}$. The separated plasma fraction is cleared protein-bound toxins by passage through columns of adsorbents. Before being returned to the patient, the plasma is pass through a standard dialysis membrane to eliminate water soluble toxins. ${ }^{10}$

Global Hospitals, India has claimed as the first hospital in the Asia-Pacific region who introduce liver dialysis unit, Prometheus system. ${ }^{11}$

\section{Dialive -a breakthrough}

The ALIVER (an European funded project to develop a liver dialysis machine) Consortium (Two universities, four hospitals, two foundations and four industrial partners will 
work together to deliver DIALIVE) has developed a novel and innovative liver dialysis machine (DIALIVE) that will help the liver to naturally regenerate or, where that does not prove possible, to keep patients alive and healthy until a donated liver becomes available. DIALIVE has been demonstrated to be effective in pre-clinical tests. ${ }^{12}$

Dialive removes dysfunctional albumin and endotoxins, infuses fresh, functional albumin and specifically targets systemic inflammation. Existing liver dialysis machines do not restore albumin function, have only a limited effect on systemic inflammation and do not improve survival rates. ${ }^{12}$

The DIALIVE machine will be tested in clinical settings in the UK, Germany, France and Spain over the course of the project. Patients with severe liver disease doesn't have good treatment options today. The DIALIVE technology might be the first breakthrough for many years designed to fill that gap in patient care. $^{12}$

\section{Liver dialysis - first time in Bangladesh A milestone in the medical history of Bangladesh}

Bangladesh also entered in a new era of liver disease treatment-the liver dialysis. The first successful completion of liver dialysis was done on 22 ${ }^{\text {nd }}$ March 2018 at Bangabandhu Sheikh Mujib Medical University (BSMMU). For the first time this dialysis was done for a liver cirrhosis patient named Sirajul Islam Haque (55). His bilirubin would not be reduced in any way, even with the conventional treatments. Then he was selected for dialysis and it was successfully applied. Professor Dr. Mamun al-Mahtab, Hepatology department, has started the liver dialysis in a new scientific and unique method. ${ }^{13}$

In the advanced world, during liver dialysis a lot of albumin is used, which is very expensive. Treatment with the devices, Prometheus and Mars, cost about $\$ 15,448$ for three dialysis treatments, other methods are also very costly. ${ }^{14}$ But at BSMMU they did not use this expensive methods. Their new scientific technique reduced the cost to one tenth, each time it will cost $35-40$ thousand taka only. ${ }^{13}$ As the technique is in its infancy, the prognosis of liver failure patients remain guarded.

In developed country, still liver dialysis is considered only to be a bridge to transplantation or liver regeneration (in the case of acute liver failure $)^{15,16}$ and like kidney dialysis it can not support a patient for an extended period of time (months to years). Never the less hope in near future it will be more useful, cheaper and available to everyone who need it.

\section{References}

1. M Wert. Liver dialysis proves another life-saving procedure. USA Today https://www.usatoday.com/story/news/.../2014/.../28/liver-dialysis-lifesaving.../96749..

2. Rozga J. Liver support technology:An update.Xenotransplantation Sep 2006;13:380-89

3. https://scholar.google.com/scholar?as_ylo $=2015 \& q=$ liver+dialysis\&hl= en\&as_sdt=0,14

4. http://onlinelibrary.wiley.com/cochranelibrary/search

5. RN Nigel Fealy ,RN Ian Baldwin, RN Martin Boyle.The molecular adsorbent recirculating system (MARS $®)$ : A therapy for the treatment of liver failure; review and case study; Australian Critical Care. Volume 18, Issue 3, August 2005, Pages 96-102

6. Baquerizo A, Mhoyan A, Shirwan $\mathrm{H}$, et al. Xenoantibody response of patients with severe acute liver failure exposed to porcine antigens following treatment with a bioartificial liver. Transplant Proc 1997;29:964-5. [PubMed]

7. 42. Rifai $K$, Ernst $T$, Kretschmer $U$, et al. Prometheus-a new extracorporeal system for the treatment of liver failure. J Hepatol 2003;39:984-90. [PubMed]

8. 43. Matsumura $\mathrm{KN}$, Guevara $\mathrm{GR}$, Huston $\mathrm{H}$, et al. Hybrid bioartificial liver in hepatic failure: preliminary clinical report. Surgery 1987;101:99-103. [PubMed]

9. 44. Chen SC, Hewitt WR, Watanabe FD, et al. Clinical experience with a porcine hepatocyte-based liver support system. Int J Artif Organs 1996;19:664-9. [PubMed] https://en.wikipedia.org/wiki/Liver_dialysis

10. Banares R ,Nevens F,Larsen FS et al. Extra corporeal liver support with the Molecular Adsorbent Recirculating System (MARS) in patients with acute -on -chronic liver failure.The relief study.J Hepatol 2010;52 (Supp 1):1184A.

11. New facility for liver dialysis - ANDHRA PRADESH - The Hindu. Mar 26, 2012 https://www.thehindu.com > Today's Paper > NATIONAL > ANDHRA PRADESH

12. ALIVER -- an EU funded project to develop a liver dialysis machine revealed

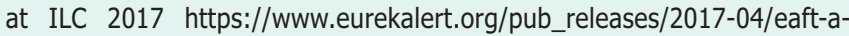
a042117.php https://steemit.com/medical/.../for-the-first-time-in-thecountry-liver-dialysis

13. Two liver dialysis machines don't extend lives | FierceBiotech Apr 16, 2010 https://www.fiercebiotech.com/...devices/two-liver-dialysis-machines-don-textend-liv...

14. O'Grady J (June 2006). "Personal view: current role of artificial liver support devices". Aliment. Pharmacol. Ther. 23 (11): 1549-57. doi:10.1111/j.13652036.2006.02931.x. PMID 16696802.

15. Neuberger J (January 2005). "Prediction of survival for patients with fulminant hepatic failure". Hepatology. 41 (1): 19-22. doi:10.1002/ hep.20562. PMID 15690476.

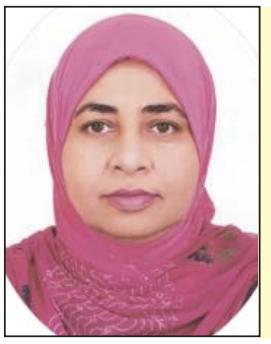

Professor Dr. B H Nazma Yasmeen, Paediatrician, working as Professor and Head, Department of Paediatrics, Northern International Medical College (NIMC) Dhaka, Bangladesh. Completed her MBBS from Sher E Bangla Medical College, Barisal. Worked at Dhaka Shishu (Children) Hospital for more than 12 years.

Editor, NIMC Journal (2009-present) and Member, International Advisory Board, Indian Journal of Trauma \& Emergency Pediatrics (2011-present). EC member: Paediatric Endocrine Society of Bangladesh. Presented scientific papers in different Paediatric Conferences of home and abroad. More than 70 Scientific Articles published in different national and International medical journals. Life Fellow: BACAMH, Life Member: BPA, BNF and Bangla Academy. Travelled over 25 Countries of the World.website:www.ProfNazma.com 